\title{
Avaliação benefício-custo de sistemas de dessalinização de água em comunidades rurais cearenses $^{1}$
}

\author{
Robério Telmo Campos*
}

Resumo: Procura-se identificar a viabilidade econômica de cinco sistemas de dessalinização por osmose reversa para o suprimento de água dessalinizada, para consumo humano, em comunidades rurais cearenses. A pesquisa foi desenvolvida no Estado do Ceará. Os dados primários foram coletados por meio de questionários e os secundários obtidos junto aos órgãos municipais e do estado. Usa-se a metodologia de análise de investimento, considerando-se o enfoque econômico. Conclui-se que a inexistência da boa prática de gestão dos sistemas resulta em inviabilidade econômica de alguns dessalinizadores, quando avaliados pelo consumo efetivo, principalmente daqueles de 400 e 600 litros/ hora, gera ineficiências no acompanhamento técnico, impossibilita melhor análise da performance dos sistemas, acarreta oferta descontínua de água e desconforto das famílias beneficiárias. Em razão das limitações impostas pelos gestores, da baixa produção e dos defeitos que trazem paralisações constantes dos aparelhos, a demanda efetiva de água restringe-se à metade do que os sistemas são capazes de produzir.

Palavras-chave: Avaliação Econômica. Sistema de Dessalinização. Água Potável.

\footnotetext{
*Doutor em Economia pela Universidade Federal de Pernambuco. roberio@ufc.br ${ }^{1} \mathrm{O}$ autor agradece ao $\mathrm{CNPq}$, que financiou a pesquisa por meio de recursos destinados pelo Edital Universal de 2001, pois dificilmente sem essa ajuda o estudo seria realizado.
} 
Classificação JEL: D61, E22 e Q25.

Abstract: This study aims to make the economic assessment of five Desalination Systems by Reverse Osmosis (RO) that are used to generate fresh water for human consumption in rural communities in the Ceará State. The data was gathered from primary source by questionnaire applied to governmental organizations. The method used was the analysis of investment taking into account shadow prices. We concluded that due to the inexistence of any good practices for the desalination management some equipment resulted in negative financing return when considering the effective consumption, particularly those of 400 and 600 liter/hour. In addition, they generated inefficiency regarding to technical support, turning impossible better improvement of the system performance, thus leading to insecure water supplies and unsatisfied demand. Given the limitations imposed by the managers, low production and system failures, which resulted in constant systems' interruption, the effective demand of fresh water was restricted to the half of the working capacity of the system.

Key words: Economic Evaluation. Desalination. Potable Water.

JEL Classificatin: D61, E22 e Q25.

\section{Introdução}

O Ceará detém 9,6\% do espaço geográfico nordestino, sendo o único estado brasileiro em que o semi-árido ocupa $93,5 \%$ da sua área total, portanto, tornando-se bastante vulnerável aos efeitos da seca.

Dados da Pesquisa Nacional por Amostras de Domicílios (PNAD), 1989, mostram que na zona rural cearense apenas 1,1\% dos domicílios eram servidos por rede geral de abastecimento de água; 59,8\% utilizavam poço ou nascente e 39,1 se supriam através de outras formas de abastecimento. Essa situação é, no mínimo, preocupante, quando se considera a necessidade de preservação dos valores sociais das comunidades afetadas, dado que os indicadores sociais relativos ao estado são muito baixos, a exemplo da mortalidade infantil; dados otimistas mostram que de 1.000 crianças nascidas vivas, 45 morrem no primeiro ano de vida.

RER, Rio de Janeiro, vol. 45, no 04, p. 963-984, out/dez 2007 - Impressa em novembro 2007 
A disponibilidade de água para o homem rural cearense reflete-se numa questão de sua própria sobrevivência. Ao longo de um século, as opções de captação para suprimento de água à população rural afetada têm sido diversas. Nobre (1985) entende que não há exagero em afirmar que o problema do suprimento de água no Nordeste brasileiro, particularmente no Ceará, é tão antigo quanto a presença humana. Assim sendo, em prevenção à escassez de água, teve início no século XVIII, por volta de 1870, o represamento das águas das chuvas ou dos rios, através da açudagem. A partir de 1975, a nova orientação política do Departamento Nacional de Obras Contra as Secas (DNOCS) foi no sentido de, além de intensificar a açudagem, incentivar a perfuração de poços em cooperação, em bases acessíveis ao homem rural da zona semi-árida. Ao longo de anos, ou décadas, essa política vem sendo alvo de críticas.

No entanto, Nobre (1985) esclarece que a salinização é uma característica verificada em toda zona semi-árida do mundo, a exemplo dos Estados Unidos da América (EUA), China, Índia, Paquistão, Egito, Sudão e na antiga União Soviética e que, em nenhum desses países a salinização desestimulou a formação de reservatórios para aproveitamento na irrigação, ou para outros usos.

A região semi-árida nordestina merece atenção especial nesse particular, tendo em vista a escassez de água potável para o consumo humano, pois Kreysing et al. (1973) dão conta de que $80 \%$ dos poços perfurados no Nordeste do Brasil apresentam teores de sais muito acima do aceitável para o consumo humano, que é de $1000 \mathrm{mg} / \mathrm{l}$, conforme a Organização Mundial de Saúde.

O problema da salinização já não causa tanto espanto na atualidade, pois Cabral Pessoa (2000) afirma que com o domínio das tecnologias de dessalinização, particularmente através do processo de membranas por osmose reversa, vem sendo possível processar as águas de altas concentrações salinas para torná-las próprias para o consumo humano.

Atualmente o número de dessalinizadores instalados no meio rural cearense é considerável. Apesar do elevado número de dessalinizadores instalados, se existe o domínio técnico de uso, faltam, no entanto, estudos de eficiência econômica e distributiva objetivando identificar a melhor opção de suprimento de água processada. Nesse sentido, uma das premissas básicas é comparar o custo do metro cúbico de água 
dessalinizada com os custos de outras opções existentes de obtenção e fornecimento de água potável.

O custo de suprimento dá indicação sobre a oferta de água em comunidades de tamanhos diferentes. Sistemas de abastecimento de água envolvem elevados investimentos e altos custos fixos. A análise de viabilidade econômica, além de possibilitar a definição do tamanho mínimo do sistema, segundo o tamanho da comunidade, serve para estabelecer critérios para eventuais políticas de tarifação, de subsídios ou de formação de poupança pela comunidade para a manutenção do sistema. Enfim, centra-se na ênfase do fortalecimento de todos os atores relevantes envolvidos com a gestão racional dos recursos hídricos, especificamente, de águas salinizadas no Estado do Ceará.

Por contar com a participação de todos, a gestão descentralizada e participativa é capaz de reduzir e até mesmo eliminar eventuais situações de descontentamento por parte da sociedade, dado que tais decisões foram tomadas respeitando-se o direito de cada segmento social influenciar o próprio processo de tomada de decisões (CARRERA-FERNANDEZ; GARRIDO, 2000, p. 608).

Assim sendo, o presente estudo procura analisar a viabilidade econômica de sistemas de dessalinização de água por osmose reversa, para consumo humano, em comunidades rurais cearenses. Para tanto, inicialmente, deve-se identificar o montante de investimento, assim como os custos de manutenção requeridos por cada sistema; calcular indicadores de viabilidade econômica; enfim, contribuir com o poder público, por meio de fundamentação econômica, para a política de gestão dos recursos hídricos no estado, no que tange à cobrança pelo uso da água dessalinizada.

\section{Metodologia}

\section{1. Área Geográfica de Estudo}

Na região Nordeste, o "Polígono das Secas" compreende uma extensão de $936.993 \mathrm{~km}^{2}$. Dos nove estados nordestinos, apenas o Ceará, Rio Grande do Norte e Paraíba estão inseridos totalmente no Polígono.

RER, Rio de Janeiro, vol. 45, no 04, p. 963-984, out/dez 2007 - Impressa em novembro 2007 
Deve-se ressaltar que dezenas e centenas de dessalinizadores foram instalados por diferentes órgãos federais voltados para os recursos subterrâneos. Os dessalinizadores selecionados para fins de estudo estão instalados em três distritos (Bonito, Ipueiras dos Gomes e Santana da Cal) pertencentes ao Município de Canindé, e em cinco distritos (Algodões, Caraúnas, Crisantemo, Pereiro e Várzea das Russas) de Quixeramobim, em razão de ambas as localidades, segundo o recenseamento das fontes de abastecimento por água subterrânea no Estado do Ceará, realizado pelo Serviço Geológico do Brasil (CPRM), que originou o "Atlas dos Recursos Hídricos Subterrâneos do Ceará”, terem, em termos de domínio hidrogeológico, a predominância de rochas cristalinas e poços de vazões de péssima qualidade de água, no que diz respeito à salinização.

\subsection{Natureza e Fonte dos Dados}

Foram utilizados, neste estudo, dados de natureza primária obtidos através de pesquisa direta, junto às famílias beneficiadas por dessalinizadores, utilizando-se a técnica de entrevista com a aplicação de questionários. Assim sendo, foram aplicados 69 questionários, distribuídos nos distritos referidos anteriormente.

Foram também utilizados dados resultantes de documentos existentes em órgãos estaduais e empresas comerciais voltados para o gerenciamento e venda de recursos hídricos no Estado do Ceará.

\subsection{Fundamentação Teórica}

Os critérios para a avaliação de opções de investimento (projetos) podem ser analisados sob os pontos de vista privado, econômico e social.

Todos buscam atingir a máxima eficiência, sendo que a avaliação privada (financeira) objetiva maximizar a eficiência dos recursos do ponto de vista do projeto; ou melhor, procura estimar a rentabilidade de um projeto em termos de recursos monetários para um agente específico (empresa, entidade financiadora, governo), sem importar se há outras pessoas ou atividades que, por sua vez, se beneficiam ou se prejudicam com esse projeto.

A avaliação financeira de um projeto investiga o retorno aos investi-

RER, Rio de Janeiro, vol. 45, no 04, p. 963-984, out/dez 2007 - Impressa em novembro 2007 
mentos, valorando os custos e os benefícios a preços de mercado. Consideram-se, assim, todos os custos (de investimentos e operacionais) e receitas, avaliados com base nos preços de mercado, incluindo impostos e/ou subsídios. Como se trata de uma análise de investimento, envolvendo, portanto, um horizonte temporal, os preços devem ser expressos em termos reais, isto é, em relação a um determinado ponto no tempo.

A rigor, a análise financeira de um projeto ou empreendimento estima o impacto que a sua implementação exercerá sobre a situação atual da empresa, projeto ou mercado.

Desta forma, se o objetivo for mensurar o retorno aos investimentos do projeto, cria-se um fluxo de caixa a partir do qual se calculam os indicadores de rentabilidade desejados (taxa interna de retorno, relação benefício/custo, valor presente líquido, entre outros). No caso de projetos públicos ligados à área de abastecimento, a elaboração do fluxo de caixa requer, inicialmente, a quantificação de várias variáveis, destacando-se entre elas, a população a ser atendida, a demanda e a oferta de água, os custos (investimentos e operação) e as receitas.

A avaliação econômica mede a rentabilidade de um projeto em termos de recursos reais para a sociedade como um todo. Assim sendo, maximiza a eficiência na alocação dos recursos sociais do ponto de vista da economia como um todo, ou seja, leva em conta a contribuição do projeto ao bem-estar econômico nacional em termos de crescimento do produto nacional, geração de emprego e formação de divisas.

Diferentemente da avaliação financeira, a avaliação econômica investiga a rentabilidade de um projeto público considerando o verdadeiro valor dos bens ou serviços e fatores de produção.

Neste sentido, os benefícios econômicos de um projeto de abastecimento de água para consumo humano têm como base o valor relativo à disponibilidade adicional ou incremental de água para os usuários e os custos financeiros serão transformados em econômicos por meio de fatores de conversão.

Duas metodologias são propostas para o cálculo dos fatores de conversão. Elas diferem quanto à forma de definição do numerário, pois uma delas tem origem do trabalho da ONUDI, de autoria de Dasgupta, Sen e Marglin (1972), e a outra, de um estudo da OCDE, de Little e Mirrlees (1968), posteriormente desenvolvido por Squire e Van der Tak 
(1975) no Banco Mundial (BIRD), traduzido para português em 1979. O numerário consiste na renda adicionada ou diminuída por cada ação econômica, ou seja, é o padrão de medida das atividades econômicas. Portanto, na avaliação financeira (privada), o numerário corresponde ao padrão monetário utilizado para medir os gastos e os ganhos de cada atividade. Neste caso, os preços de mercado são suficientes como indicadores de custos e benefícios. Já em termos econômicos, essa medição é insuficiente, sendo necessário determinar os chamados preços-sombra (ou preços de conta), que indicam o valor de cada produto, insumo ou serviço medido com base no numerário definido em correspondência aos custos econômicos de oportunidade desses bens e serviços (BUARQUE, 1991). Uma outra metodologia deve-se a Harberguer, conhecida como o enfoque da Universidade de Chicago (CONTADOR, 2000).

A concepção do numerário da OCDE e Banco Mundial parte do princípio de que o custo de oportunidade de qualquer atividade econômica dentro de um país é dado pelo ganho ou perda dessa economia em relação ao exterior, em razão da produção ou do uso de insumos na atividade em questão, ou seja, consiste na disponibilidade líquida de divisas decorrentes do projeto.

Segundo essa óptica, pode-se atribuir o valor em divisas para um fator de produção por meio da análise de quantas divisas poderia gerar o referido fator em seu melhor uso alternativo. O valor do fator (ou preço-sombra) é seu custo de oportunidade, medido em divisas; esta é a primeira tarefa a se realizar.

Na prática, o preço-sombra é definido por meio de uma relação denominada de Fator de Conversão (FC), em que: FC = Preço-sombra do bem i / Preço de mercado do bem i.

Em seguida, ao se multiplicar o preço de mercado do bem (ou insumo) ou o valor registrado na avaliação financeira pelo FC, obtém-se o preço-sombra desse bem (ou insumo).

A avaliação social, embora não seja objetivo deste trabalho, difere da avaliação econômica em razão de que, além de medir o impacto de um projeto sobre o consumo, a poupança e os bens públicos/semi-públicos, identifica e valoriza o efeito do projeto sobre a distribuição de renda e riqueza. Assim, na avaliação social leva-se em conta a redistribuição.

Tudo que concerne à avaliação econômica ou de eficiência também

RER, Rio de Janeiro, vol. 45, no 04, p. 963-984, out/dez 2007 - Impressa em novembro 2007 
é aplicável à avaliação social. No entanto, na avaliação social mede-se a utilidade marginal gerada por um determinado bem para diferentes indivíduos ou grupos. Ou seja, a Utilidade Marginal (UMg) de um bem varia segundo a pessoa que o consome.

\subsection{Métodos de Análise}

Tratando-se de análise econômico-financeira, um "projeto de investimento" é qualquer atividade produtiva de vida limitada, que implique a imobilização de alguns recursos financeiros, na forma de bens de produção, em determinado momento, na expectativa de gerar recursos futuros oriundos da produção (NORONHA; DUARTE, 1995). Assim sendo, este tipo de conceituação possibilita a quantificação dos investimentos, dos insumos e dos produtos associados ao projeto (FARO, 1972).

Para a análise de rentabilidade desses projetos, consideram-se os fluxos de entrada de caixa ou de receita e o de saída de caixa ou de custo, que se verificam no horizonte de planejamento do projeto.

\subsubsection{Avaliação Financeira}

\section{Quantificação dos Benefícios (B)}

Determinam-se as quantidades de bens que o projeto produzirá em cada unidade de tempo futura e se multiplicam essas quantidades pelos respectivos preços de mercado. No presente caso, o fluxo anual de benefícios (receitas) é estimado multiplicando-se a demanda/oferta de água anual por diferentes tarifas, simuladas de acordo com as opções

que se apresentam à comunidade objeto de estudo. É pensamento inicial usar tarifas cobradas pela Superintendência de Obras Hidráulicas (SOHIDRA) ou, em alguns casos, tarifas estipuladas pela própria comunidade beneficiada. Outra opção é utilizar a disposição a pagar (DAP) por água dessalinizada, que está sendo objeto de outro estudo na Universidade Federal do Ceará.

Na aplicação da tarifa, deve-se considerar também a faixa de renda dos residentes (baixa e alta renda) e a participação relativa dos residentes por faixa de renda na população.

RER, Rio de Janeiro, vol. 45, no 04, p. 963-984, out/dez 2007 - Impressa em novembro 2007 


\section{Quantificação dos Custos (C)}

Determinam-se os investimentos e os custos operacionais, com suas respectivas quantidades, vidas úteis e preços de mercado.

Os investimentos propostos são separados por tipo (abrigo, muro, rede elétrica, sistema de captação, adutora e dessalinizador) e desagregados em serviços preliminares, tubos e conexões, obras civis, equipamentos, serviços etc.

Os custos operacionais que resultam da operação e manutenção do sistema são distribuídos entre aqueles que ocorrem mesmo quando o sistema está paralisado, isto é, independem do volume anual de produção de água (mão-de-obra permanente, peças de reposição anuais etc), e aqueles que são proporcionais ao volume de água produzido (energia, produtos químicos e material de limpeza).

\section{Fluxo de Caixa}

O fluxo de caixa representa um resumo de todos os cálculos realizados anteriormente, considerando-se o fluxo anual dos benefícios (receitas) e o fluxo anual dos custos, inclusive dos investimentos, para todo o horizonte de planejamento do projeto. A formalização deste fluxo servirá de base para se estimar os indicadores de rentabilidade financeira.

\subsubsection{Avaliação Econômica}

Uma vez realizada a avaliação financeira, procede-se a avaliação econômica. Sob condições de concorrência perfeita, a avaliação financeira (AF) seria igual à avaliação econômica (AE), ou seja, nenhuma conversão de valores seria necessária. No entanto, principalmente para países em desenvolvimento, observa-se imperfeição dos mercados, assim como a ausência de mecanismos de regulamentação nos países mais desenvolvidos; a sujeição dessas economias acarreta desequilíbrios, em particular no que se refere à disponibilidade e utilização dos fatores; e as dificuldades de controle e internalização das externalidades nessas economias tornam insuficiente a condição de concorrência perfeita para a obtenção de uma alocação eficiente de recursos no sentido paretiano ${ }^{2}$.

${ }^{2} \mathrm{O}$ conceito de Pareto de eficiência econômica diz que fora do equilíbrio competitivo "pelo menos um indivíduo fica melhor sem que nenhum indivíduo da sociedade fique em

RER, Rio de Janeiro, vol. 45, no 04, p. 963-984, out/dez 2007 - Impressa em novembro 2007 
Portanto, admitem-se distorções no mercado que podem ser corrigidas por meio da utilização de preços-sombra (POMERANZ, 1988).

Em síntese, tem-se que, na prática, duas situações podem ocorrer:

a) Existe preço de mercado, mas difere do seu custo de oportunidade $\Rightarrow \mathrm{AF} \neq \mathrm{AE}$

b) Não existem preços de mercado, bens públicos $\Rightarrow \mathrm{AF} \neq \mathrm{AE}$

A seguir, descrevem-se os procedimentos adotados nas duas situações:

\section{a) Projetos em que existem preços de mercado para bens e/ou serviços}

O primeiro passo é transformar os benefícios financeiros (BF) em benefícios econômicos (BE) esperados para cada ano do horizonte de planejamento do projeto, em R \$/ano.

Quantificação dos Benefícios (BE):

$B E=\sum_{i=1}^{n} P_{F i} \cdot F C_{i} \cdot Q_{i}$

onde:

$\mathrm{P}_{\mathrm{Fi}}=$ preço financeiro ou de mercado do bem ou serviço $\mathrm{i}$;

$\mathrm{FC}_{\mathrm{i}}=$ fator de conversão;

$\mathrm{Q}_{\mathrm{i}}=$ quantidade do bem ou serviço $\mathrm{i}$.

Em seguida, transformam-se os custos financeiros em custos econômicos (CE) para cada ano do horizonte de planejamento do projeto, em R\$/ano.

Quantificação dos Custos Econômicos (CE):

$$
\mathrm{CE}=\sum_{\mathrm{j}=1}^{n} \mathrm{P}_{\mathrm{fj}} \cdot \mathrm{FC}_{\mathrm{j}} . \mathrm{S}_{\mathrm{j}}
$$

onde:

situação pior”. Devido ao rigor, esse princípio foi substituído pelo da melhoria potencial de Pareto, que incorpora o princípio da compensação de Kaldor e Hicks, formando a base da avaliação econômica. Ou seja, quem ganha (beneficiados com o projeto) com as mudanças propiciadas pelo projeto pode potencialmente compensar quem perde (perdedores) e ainda assim ficar em situação melhor. Dadas as configurações que determinam o equilíbrio, sob concorrência perfeita, processa-se a aplicação mais eficiente ou ótima dos recursos, identificada com o critério paretiano: em equilíbrio, nenhuma melhoria pode ser realizada, sem que alguém fique em situação pior (POMERANZ, 1988).

RER, Rio de Janeiro, vol. 45, no 04, p. 963-984, out/dez 2007 - Impressa em novembro 2007 
$\mathrm{P}_{\mathrm{fj}}=$ preço financeiro do insumo $\mathrm{j}$;

$\mathrm{FC}_{j}=$ fator de conversão;

$\mathrm{S}_{\mathrm{j}}=$ quantidade utilizada do insumo $\mathrm{j}$.

b) Projetos em que não existem preços de mercado (bens públicos) Quantificação dos Benefícios (BE):

Seguem-se os seguintes passos:

- Calcula-se a disposição a pagar (DAP)

- Calculam-se os benefícios econômicos $\left(\mathrm{BE}_{\mathrm{k}}\right)$

$\mathrm{BE}_{\mathrm{k}}=\mathrm{FC} \times \mathrm{DAP} \times \mathrm{N}_{\mathrm{k}}$

onde:

$\mathrm{BE}_{\mathrm{k}}=$ benefício econômico esperado do bem para o k-ésimo ano do projeto, R\$/ano;

FC $=0,94 \rightarrow$ representa o fator de conversão padrão para transformar o valor financeiro da Disposição a Pagar (DAP) em valor econômico.

DAP = disposição média a pagar pelo bem, anualmente, por parte das famílias residentes, $\mathrm{R}$ /família/ano;

$\mathrm{N}_{\mathrm{k}}$ = famílias residentes no k-ésimo ano do projeto, expresso em número de famílias.

Quantificação dos Custos:

É semelhante ao procedimento anterior, ou seja,

$$
C E_{k}=\sum_{l=1}^{n} P_{f l} \cdot F C_{l} \cdot S_{l}
$$

onde:

$\mathrm{CE}_{\mathrm{k}}=$ custo econômico do projeto no k-ésimo ano, R\$/ano;

$\mathrm{P}_{\mathrm{fl}}=$ preço financeiro ou de mercado do insumo l;

$\mathrm{FC}_{1}=$ fator de conversão de cada insumo;

$\mathrm{S}_{1}=$ quantidade utilizada do insumo 1 .

\subsubsection{Indicadores de Avaliação Econômica}

Para fins de avaliação econômica, os fluxos de benefícios financeiros, sob o ponto de vista do empresário/entidade, são transformados em fluxos econômicos, sob a óptica da economia em geral/sociedade. Nesta transformação, o fluxo de benefícios é ajustado, considerando-se 
tarifas representativas do preço econômico da água. Por sua vez, para o fluxo de custos aplicam-se os preços-sombra sobre os itens de capital, nacionais ou importados, e sobre os custos operacionais (insumos e mão-de-obra), excluindo impostos, subsídios, juros de financiamentos, depreciações, aluguéis e preço do terreno do local do dessalinizador, considerados como meras transferências.

Para avaliação dos retornos aos investimentos, utilizam-se os seguintes indicadores de rentabilidade, assim descritos: a) a relação benefício-custo econômica (RBC) é definida como o quociente entre o valor atual do fluxo de benefícios econômicos a serem obtidos e o valor atual do fluxo de custos econômicos, incluindo os investimentos necessários ao desenvolvimento do sistema de dessalinização (HOFFAMNN et al., 1987). A proposta de investimento será descartada, por esse critério, caso a RBC seja menor do que 1. O indicador RBC é muito utilizado e de interpretação relativamente fácil em comparação com outros indicadores. No entanto, a sua obtenção depende da fixação a priori de uma taxa mínima de atratividade ou custo de oportunidade, a ser utilizada como taxa social de desconto dos fluxos, o que, em geral, se pode realizar com algum grau de arbitrariedade (AZEVEDO FILHO, 1988; CARRERA-FERNANDEZ; GARRIDO, 2002).

A taxa mínima de atratividade deve representar o que se deixa de ganhar pela não aplicação do capital a ser investido em outra opção disponível (FARO, 1972). Neste estudo, utiliza-se como taxa mínima de atratividade a taxa usual de desconto de $12 \%$ ao ano (CARRERAFERNANDEZ, 2000). Esta taxa, considerada alta, por alguns estudiosos, para as condições de escassa aplicação e baixa rentabilidade dos ativos no mercado rural nordestino, tem seu uso incentivado pelo Banco Mundial (BIRD), quando dos financiamentos de programas e projetos que envolvem recursos hídricos na Região.

O valor presente líquido econômico (VPL) de um projeto é definido como a soma algébrica dos valores do fluxo líquido econômico de caixa a ele associado, atualizados a uma adequada taxa de desconto, a qual deve corresponder ao custo de oportunidade social do capital. O investimento será considerado viável se o VPL for positivo. Neste caso, pode-se dizer que o capital investido (inclusive os custos incluídos para fins de análise econômica) será: recuperado, remunerado à taxa de 
desconto considerada ou gerará um lucro extra na data zero, igual ao VPL (LAPPONI, 1996). A atividade será tanto mais interessante quanto maior for o seu VPL (FARO, 1972).

A taxa interna de retomo econômica (TIRE) é definida como o valor da taxa de desconto ( $\mathrm{r}$ ) que torna o valor presente dos benefícios econômicos igual ao valor presente dos custos econômicos (NORONHA, 1987; BUARQUE, 1991). A rejeição de um projeto através da TIRE será recomendável quando o seu valor for inferior ao custo de oportunidade do capital. O cálculo do Custo Unitário de Produção (CUP) foi considerado conforme Azevedo Filho (1988).

\section{Resultados e discussão}

Diferentemente da avaliação financeira, na avaliação econômica determina-se a rentabilidade de uma proposta de investimento ou projeto público considerando-se o verdadeiro valor dos bens, serviços e fatores de produção. Conforme descrito, esse valor pode ser chamado shadow price, preço de eficiência, preço-de-conta ou preço econômico, que representa o custo de oportunidade do capital para a sociedade.

Assim sendo, os benefícios econômicos de cada sistema de dessalinização de abastecimento de água potável para consumo humano deve levar em conta o valor relativo adicional de água para os usuários, sendo que os custos financeiros do sistema devem ser transformados em econômicos através de fatores de conversão.

Os fatores de conversão usados neste estudo para a transformação dos preços financeiros em preços econômicos são os mesmos utilizados em avaliação de programas de beneficiamento de água e esgotos no Nordeste do Brasil pelo Banco Mundial (BIRD).

Estes fatores estão assim distribuídos:

- Mão-de-obra qualificada $\quad 0,81$

- Mão-de-obra não-qualificada $\quad 0,46$

- Materiais nacionais ou importados $\quad 0,88$

- Máquinas e equipamentos nacionais ou importados $\quad 0,80$

- Produtos químicos $\quad 0,83$

- Energia elétrica $\quad 0,97$

RER, Rio de Janeiro, vol. 45, no 04, p. 963-984, out/dez 2007 - Impressa em novembro 2007 
- Fator de conversão padrão ou para blocos de produtos similares (FCP)

\subsection{Investimentos e Custos Operacionais}

Ressalta-se que os orçamentos inerentes a cada dessalinizador e à infra-estrutura de cada sistema de dessalinização foram inicialmente preparados para fins de avaliação financeira. Em seguida, esses orçamentos foram ajustados, ou seja, foram convertidos a preços econômicos para fins de avaliação econômica. Antes de se iniciar a conversão, alguns itens de capital, insumos e serviços que faziam parte da tabela a preços financeiros tiveram que ser desagregados para a aplicação específica de cada fator de conversão, assim como alguns deles foram excluídos por representarem transferências (ver item 2.5.3). Desta forma, as infra-estruturas de cada sistema, acrescida do dessalinizador, resultaram nos seguintes valores: $\mathrm{R} \$ 16.935,06$ para o sistema tipo I (400 litros/hora), R\$ 18.215,06 para o sistema tipo II (600 litros/hora), R \$ 20.092,69 para o tipo III (800 litros/hora), R $\$ 22.905,83$ para o tipo IV (1.200 litros/hora) e de $\mathrm{R} \$ 26.745,83$ para o sistema de dessalinização tipo V (vazão de 1800 litros/hora).

O procedimento adotado para calcular os custos de operação e manutenção, a preços econômicos, foi o mesmo adotado para os investimentos. Desta forma, partindo-se das tabelas usadas para a avaliação financeira, encontram-se os custos econômicos, transformados através dos respectivos fatores de conversão para preços econômicos.

Assim sendo, os custos a preços de conta foram da ordem de R \$ $2.169,50$ para o sistema tipo I, R \$2.266,35 para o sistema tipo II, R\$ $2.346,15$ para o tipo III, $\mathrm{R} \$ 3.062,63$ para o tipo IV e de $\mathrm{R} \$ 3.461,55$ para o sistema de dessalinização tipo $\mathrm{V}$.

\subsection{Receitas Econômicas}

Para o cálculo das receitas a preços econômicos, usam-se as tarifas observadas a partir das informações acerca do sistema atualmente em operação junto à comunidade beneficiária. Quando da avaliação financeira, a tarifa oficial vigente, cobrada por meio de ficha (1 ficha

RER, Rio de Janeiro, vol. 45, no 04, p. 963-984, out/dez 2007 - Impressa em novembro 2007 
$=\mathrm{R} \$ 0,10$ para 20 litros d'água), era de $\mathrm{R} \$ 5,00 / \mathrm{m}^{3}$, com proposta de elevação, pela SOHIDRA, para $\mathrm{R} \$ 10,00 / \mathrm{m}^{3}$. Estas duas tarifas são usadas para fins de simulação. Desta forma, cada tarifa, a preço financeiro ou de mercado, é multiplicada pelo fator de conversão padrão de 0,94, encontrando-se as tarifas, a preço econômico, de $\mathrm{R} \$ 4,70 / \mathrm{m}^{3}$ e $\mathrm{R} \$$ 9,40/ $\mathrm{m}^{3}$, respectivamente.

Os fluxos anuais de receitas a preços econômicos, semelhantemente ao procedimento adotado para a avaliação financeira, foram estimados multiplicando-se a demanda efetiva anual de água de cada sistema pelas tarifas, a preços econômicos, referidas anteriormente. Essa demanda ou consumo efetivo de água varia de $463,08 \mathrm{~m}^{3}$ /ano para o sistema do tipo I até $2.304 \mathrm{~m}^{3}$ /ano para o sistema do tipo V (Tabela 1). Na mesma Tabela apresentam-se as receitas potenciais, calculadas considerandose a produção potencial de cada dessalinizador em oito horas de funcionamento diário.

Deve-se ressaltar que em pesquisa realizada pela SRH (2001) nos municípios cearenses de Itapiúna, Capistrano, Mulungu e Aratuba, consumidores não conectados à rede pública de abastecimento de água supriam suas necessidades através de fontes opcionais, tais como poços tubulares, carros-pipa, buscavam água e, não raro, compravam água. A mesma pesquisa em âmbito domiciliar identificou que em Itapiúna/Capistrano $89 \%$ das famílias buscavam água em açude e $11 \%$ compravam, indicando um custo alternativo da água, a preços financeiros, de $\mathrm{R} \$$ $6,76 / \mathrm{m}^{3}$. Já nas comunidades serranas de Aratuba e Mulungu 37,14\% usavam como fonte poços e $62,46 \%$ buscavam água em açude, resultando em uma tarifa média de $\mathrm{R} \$ 6,53 / \mathrm{m}^{3}$. Estas tarifas, a preços econômicos, ficaram na ordem $\mathrm{R} \$ 6,35 / \mathrm{m}^{3}$ e $\mathrm{R} \$ 6,14 / \mathrm{m}^{3}$, respectivamente.

Constata-se, portanto, que estas tarifas estão dentro dos limites de cobrança recomendados pela SOHIDRA. Além disso, como já discutido, a água dessalinizada tem padrão de qualidade superior à água adquirida e consumida por aquelas comunidades.

\subsection{Fluxos de Caixa}

Várias tabelas de fluxos de caixa foram preparadas para fins de avaliação econômica, envolvendo quatro simulações; duas delas são fei-

RER, Rio de Janeiro, vol. 45, no 04, p. 963-984, out/dez 2007 - Impressa em novembro 2007 
tas considerando-se o consumo efetivo de água pelas comunidades em cada sistema e as outras duas levando-se em conta a capacidade produtiva potencial; em ambas as simulações usam-se as tarifas para fins de avaliação econômica de $\mathrm{R} \$ 4,70 / \mathrm{m}^{3}$ e $\mathrm{R} \$ 9,40 / \mathrm{m}^{3}$.

\subsubsection{Indicadores Econômicos}

A Tabela 2 apresenta os resultados dos indicadores econômicos, envolvendo as quatro simulações, para todos os sistemas de dessalinização analisados.

O dessalinizador do tipo I mostra-se viável quando se efetua o cálculo pela produção potencial e as tarifas de $\mathrm{R} \$ 5,00 / \mathrm{m}^{3}$ e $\mathrm{R} \$ 10,00$ / $\mathrm{m}^{3}$. As relações B/C são maiores do que 1; os VPL's são positivos e as TIRE's são superiores ao limite aceitável pelo Banco Mundial (BIRD), de $12 \%$ ao ano. O custo unitário da água é de $\mathrm{R} \$ 10,58 / \mathrm{m}^{3}$ calculado pelo consumo efetivo e de $\mathrm{R} \$ 4,20 / \mathrm{m}^{3}$ quando se estima pela produção potencial do dessalinizador.

Tabela 1 - Demonstrativo das receitas, a preços econômicos, de cada sistema de dessalinização por osmose reversa segundo o consumo efetivo e a produção potencial, Ceará, nov./2002.

\begin{tabular}{|c|c|c|c|c|c|}
\hline $\begin{array}{c}\text { Tipo de } \\
\text { Dessalinizador }\end{array}$ & $\begin{array}{c}\text { Consumo } \\
\text { Efetivo } \\
\left(\mathrm{m}^{3} / \mathrm{ano}\right) \\
\end{array}$ & $\begin{array}{l}\text { Produção } \\
\text { Potencial } \\
\left(\mathrm{m}^{3} / \text { Ano) }\right.\end{array}$ & $\begin{array}{c}\text { Tarifa } \\
\left(\mathrm{R} \$ / \mathrm{m}^{3}\right)\end{array}$ & $\begin{array}{c}\text { Receita } \\
\text { Efetiva } \\
\text { (R\$/Ano) }\end{array}$ & $\begin{array}{c}\text { Receita } \\
\text { Potencial } \\
\text { (R\$/Ano) }\end{array}$ \\
\hline \multirow{2}{*}{ Tipo I (400 l/h) } & 463,08 & $1.168,00$ & 4,70 & $2.176,48$ & $5.489,60$ \\
\hline & 463,08 & $1.168,00$ & 9,40 & $4.352,95$ & $10.979,20$ \\
\hline \multirow{2}{*}{ Tipo II (600 l/h) } & 467,40 & $1.752,00$ & 4,70 & $2.196,78$ & $8.234,40$ \\
\hline & 467,40 & $1.752,00$ & 9,40 & $4.393,56$ & $16.468,80$ \\
\hline \multirow{2}{*}{ Tipo III (800 l/h) } & 906,24 & $2.336,00$ & 4,70 & $4.259,33$ & $10.979,20$ \\
\hline & 906,24 & $2.336,00$ & 9,40 & $8.518,66$ & $21.958,40$ \\
\hline \multirow{2}{*}{ Tipo IV (1200 l/h) } & $1.882,68$ & $3.504,00$ & 4,70 & $8.848,60$ & $16.468,80$ \\
\hline & $1.882,68$ & $3.504,00$ & 9,40 & $17.697,19$ & $32.937,60$ \\
\hline \multirow{2}{*}{ Tipo V (1800 l/h) } & $2.304,00$ & $5.256,00$ & 4,70 & $10.828,80$ & $24.703,20$ \\
\hline & $2.304,00$ & $5.256,00$ & 9,40 & $21.657,60$ & $49.406,40$ \\
\hline
\end{tabular}

Fonte: Dados da pesquisa. Cálculos do autor. 
Robério Telmo Campos 979

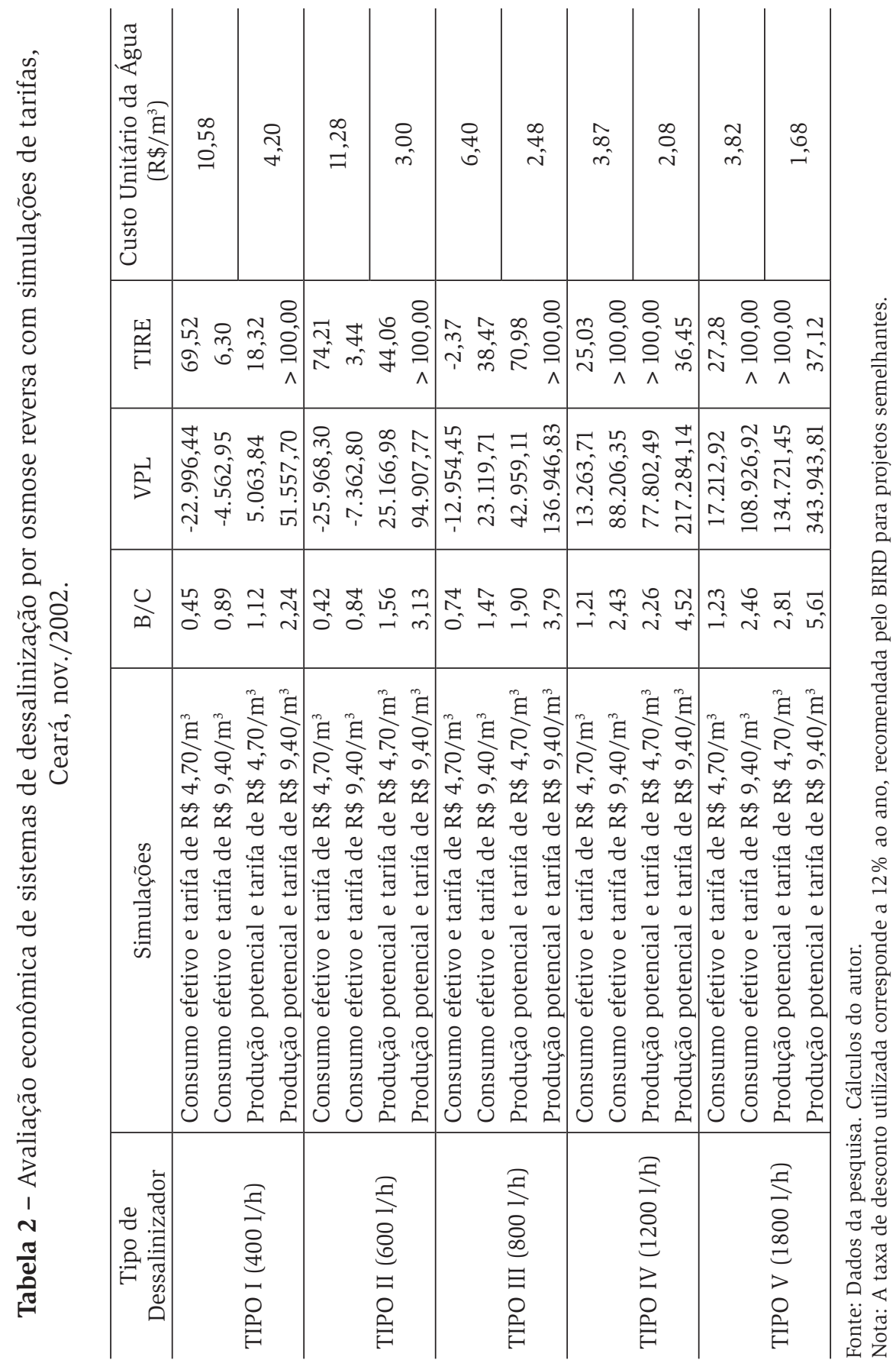

RER, Rio de Janeiro, vol. 45, no 04, p. 963-984, out/dez 2007 - Impressa em novembro 2007 
Levando-se em conta a demanda efetivamente observada, o custo do $\mathrm{m}^{3}$ de água situa-se acima da tarifa econômica de $\mathrm{R} \$ 9,70 / \mathrm{m}^{3}$, e tanto a relação B/C quanto o VPL apresenta-se na faixa de inviabilidade.

O sistema do tipo II é viável também apenas no caso de o aparelho funcionar em sua capacidade de produção potencial. Nesta situação, todos os indicadores localizam-se dentro dos limites aceitáveis e o custo do $\mathrm{m}^{3}$ de água dessalinizada é de apenas $\mathrm{R} \$ 3,00$.

O sistema do tipo III mostra-se inviável apenas quando se considera o consumo efetivo e a tarifa de $\mathrm{R} \$ 4,70 / \mathrm{m}^{3}$. A TIRE, apesar de suas limitações, no presente caso, como medida de tomada de decisão, é de -2,37; no entanto, embora negativa apresenta-se em nível aceitável, por se tratar de um projeto de cunho eminentemente social e situar-se em patamar superior ao limite aceitável pelo Programa de Desenvolvimento Sustentável de Recursos Hídricos para o Semi-Árido Brasileiro (PROÁGUA Semi-Árido), que é de $-5 \%$. O custo do $\mathrm{m}^{3}$ de água é de $\mathrm{R} \$$ 6,40 e $\mathrm{R} \$ 2,48$, calculado pelo consumo efetivo e pela produção potencial, respectivamente.

O sistema do tipo IV apresenta-se viável para todos os indicadores e simulações realizadas. O custo do $\mathrm{m}^{3}$ de água, da ordem de $\mathrm{R} \$ 3,87$ calculado pelo consumo efetivo, e de $\mathrm{R} \$ 2,08$ quando estimado pela produção potencial, é inferior à tarifa mais baixa, de $\mathrm{R} \$ 4,70 / \mathrm{m}^{3}$, a preços econômicos.

O sistema do tipo V (vazão de 1800 litros de água potável por hora) é o que apresenta melhor viabilidade econômica relativamente aos demais sistemas analisados. Todos os indicadores apresentam-se viáveis, em limites bem superiores aos recomendados em estudos semelhantes e, comparativamente, aos demais sistemas objeto do presente estudo. $\mathrm{O}$ custo unitário da água foi também o mais baixo, sendo da ordem de $\mathrm{R} \$$ $3,82 / \mathrm{m}^{3}$ calculado pela demanda efetiva e de $\mathrm{R} \$ 1,68 / \mathrm{m}^{3}$ quando estimado pela capacidade produtiva potencial desse sistema de dessalinização.

\section{Conclusões e sugestões}

Partindo-se da análise dos resultados, deduz-se que dos itens de capital que compõem o valor total dos investimentos em sistemas de dessalinização por osmose reversa, o aparelho (dessalinizador) representa

RER, Rio de Janeiro, vol. 45, no 04, p. 963-984, out/dez 2007 - Impressa em novembro 2007 
maior percentual e, na formação dos seus custos, o valor das membranas chega atingir o percentual de até $67 \%$ do valor total do aparelho de vazão de 1.800 litros/hora.

Os órgãos voltados para a gestão dos dessalinizadores não adotam ou não recomendam os operadores do sistema a efetuar anotações mensais ou anuais de reposições de peças e as conseqüentes despesas efetivamente realizadas em cada sistema, o que acarreta ineficiências no acompanhamento técnico, impossibilidade de melhor análise da performance do sistema, oferta descontínua de água, desconforto das famílias, enfim, a quase inexistência da boa prática de gestão dos recursos hídricos.

A estipulação de uma tarifa única, para todos os distritos/municípios, ainda não se constitui prática uniforme adotada pelos órgãos gestores. Em um mesmo município, como é o caso de Quixeramobim, verifica-se a cobrança de tarifas diferenciadas em distritos/comunidades diferentes. Em contraposição, no município de Canindé nenhuma tarifa é paga pelo uso da água dessalinizada.

A demanda efetiva de água dessalinizada não atinge a metade do que os aparelhos são capazes de produzir. Esta constatação deve-se aos problemas de oferta ocasionados pelos seguintes fatores: as limitações impostas pelas "autoridades gestoras" quanto ao volume de água disponível por família, no máximo de 40 litros/dia; a baixa produção (processamento) de água ocasionada por poucas horas de funcionamento, em média 3 a 4 horas/dia; e ao elevado tempo de paralisação de certos aparelhos, ocasionado, na maioria das vezes, por pequenos defeitos.

A análise de viabilidade econômica mostra que tanto o sistema de dessalinização do tipo I quanto o do tipo II, nas atuais condições de uso, são inviáveis ao se considerar no cálculo das receitas o consumo efetivo das famílias, ou melhor, o consumo sub-otimizado. Na verdade, ambos são viáveis quando se considera a produção potencial ou o consumo otimizado pelo número de famílias que podem ser supridas com água por cada aparelho.

Os demais sistemas são todos viáveis, à exceção do sistema composto pelo dessalinizador de vazão de 800 litros por hora, que é inviável apenas quando se considera o consumo efetivo e a tarifa de $R \$ 4,70 / \mathrm{m}^{3}$, sendo viáveis nas demais simulações.

$\mathrm{O}$ custo do $\mathrm{m}^{3}$ da água dessalinizada, para os aparelhos com vazões

RER, Rio de Janeiro, vol. 45, no 04, p. 963-984, out/dez 2007 - Impressa em novembro 2007 
superiores a 800 litros/hora, situa-se dentro dos padrões aceitáveis de cobrança vigente junto às comunidades pesquisadas. Em Quixeramobim, o $\mathrm{m}^{3}$ de água fornecida por carro-pipa custou aos cofres públicos $\mathrm{R} \$ 5,76$. Vale salientar que essa água normalmente é proveniente de açude, contaminada de impurezas e coliformes fecais, sem receber qualquer forma de tratamento para ser distribuída. Portanto, é de baixa qualidade, além de ser esporádica, pois depende de várias iniciativas, a começar do governo estadual. Em contrapartida, o dessalinizador fornece água de qualidade muito superior, em padrão comparável ao da água mineral comercializada por muitas empresas da iniciativa privada no Brasil.

Enfim, sugerem-se outros estudos para fins de constatação dos benefícios que são atribuídos ao uso da tarifa mais baixa, de $\mathrm{R} \$ 4,70 / \mathrm{m}^{3}$ água dessalinizada, como a diminuição do índice de mortalidade infantil, redução dos internamentos hospitalares, de infecções por diarréia, de exames laboratoriais, de gastos com remédios, dos índices de hipertensos, além de proporcionar a melhora sensível de pessoas que sofrem de problemas renais. A escassez de água comum na região, associada à oportunidade rara de ter água de boa qualidade, também serve para disciplinar as pessoas a fazer uso racional desse recurso, evitando os desperdícios.

\section{Referências bibliográficas}

\section{AZEVEDO FILHO, A.J.B.V. ALEAXPRJ - Sistema para simulação e análise econômica de projetos em condições de risco. Piracicaba: USP, 1988. 158p.}

BISERRA, J.V. Projeto executivo da adutora de Iguatu: avaliação financeira e econômica. Fortaleza: Secretaria de Recursos Hídricos do Estado do Ceará. s.d. 48p. (mimeo).

BUARQUE, C. Avaliação econômica de projetos: uma apresentação didática. Rio de Janeiro: Campus, 1991. 266p.

CABRAL PESSOA, L.C. Análise do desempenho e do impacto ambiental dos dessalinizadores por osmose reversa. 2000. 158f. Dissertação (Mestrado em Hidráulica) - Departamento de Engenharia Hidráulica e Ambiental, Universidade Federal do Ceará, Fortaleza, 2000. 
Robério Telmo Campos • $\mathbf{9 8 3}$

CARRERA-FERNANDEZ, J. O Princípio dos usos múltiplos dos recursos hídricos: uma análise a partir da bacia do rio Formoso no oeste baiano. Revista Econômica do Nordeste, Fortaleza, v. 31, número especial, p. 810-835, 2000.

CARRERA-FERNANDEZ, J.; GARRIDO, R. S. O Instrumento de cobrança pelo uso da água em bacias hidrográficas: uma análise dos estudos no Brasil. Revista Econômica do Nordeste, Fortaleza, v. 31, número especial, p. 604-628, 2000.

CARRERA-FERNANDEZ, J.; GARRIDO, R. S. Economia dos recursos hídricos. Salvador: Edufba, 2002. 458p.

CONTADOR, C. R. Projetos sociais: avaliação e prática. $4^{a}$ ed. Ampl., São Paulo: Atlas, 2000. 375p.

DASGUPTA, P.; SEN, A.; MARGLIN, S. Guidelines for project evaluation. New York: United Nations Industrial Development/UNIDO, 1972.

FARO, C. de. Engenharia econômica: elementos. São Paulo: APEC, 1972. 338p.

HOFFMANN, R. et al. Administração da empresa agrícola. 3 ed. São Paulo: Pioneira, 1987. 325p.

IBGE. Pesquisa Nacional por Amostras de Domicílios - PNAD. Rio de Janeiro: IBGE, 1989.

KREYSING, K. et al. Salinização das águas subterrâneas no centro do polígono das secas do Nordeste brasileiro. Recife: Divisão de Documentação/SUDENE, 1973. v.1.

LAPPONI, J.C. Avaliação de projetos de investimento: modelos em Excel. São Paulo: Lapponi Treinamento e Editora Ltda., 1996. 264p.

LITTLE, I.M.D.; MIRRLEES, J.A. Manual of industrial project analysis in developing countries. Paris: Organization for Economic Cooperation and Development/OCDE, 1968.

NOBRE, G. da S. O DNOCS em questão: análise de políticas e estratégias. In: NÚCLEO INDEPENDENTE DE ESTUDOS E PESQUISAS DO CEARÁNIEPCE. O DNOCS e o novo Nordeste: uma perspectiva histórica, 19091984. Fortaleza: DNOCS, 1985. v. 2.

RER, Rio de Janeiro, vol. 45, no 04, p. 963-984, out/dez 2007 - Impressa em novembro 2007 
NORONHA, J.F. Projetos agropecuários: administração financeira, orçamentária e viabilidade econômica. 2 ed., São Paulo: Atlas, 1987. 269p.

NORONHA, J.F.; DUARTE, L.P. Avaliação de projetos de investimentos na empresa agropecuária. In: AIDAR, A. C. K. (org.). Administração rural. São Paulo: Paulicéia, 1995. p. 213-251.

POMERANZ, L. Elaboração e análise de projetos. $2^{\mathrm{a}}$ ed., São Paulo: Hucitec, 1988. 246p.

SECRETARIA DE RECURSOS HÍDRICOS (SRH) do Estado do Ceará. PROÁGUA semi-árido: estudos de avaliação financeira e econômica da barragem pesqueiro. Fortaleza: SRH, 2001.

SQUIRE, L.; van der TAK, H. G Análise econômica de projetos. Rio de Janeiro: Livros Técnicos e Científicos, 1979. 149p.

Recebido em janeiro de 2005 e revisto em março de 2007. 